3. With the constant element in the current--

(a) With the positive pole against the apparatus.

(b) With the positive pole against the disk in the earth.

The deflexions obtained will give the particulars required for an easy calculation of the strength of the current from the atmosphere to the earth.

I am fully aware that several details of this method may be open to discussion, but I do not deem others than the following of any great importance, viz. that as the intensity of the current is greatly dependent on the condition of the points, a gradual oxidation of the same will have the effect of causing an alteration in the current. This alteration also takes place in the strength of the current from the c instant element, so that even the deflexions caused by the same will always be a measure of the aggregate potential due to induction, both through the points and in the air.

As it is not always possible to calculate the extent of the deflexions, an instrument permitting part of the current to be shunted should be employed. When the apparatus is erected care should be taken that the beight between the disk in the earth and the apparatus is at least I 80 metres; but experiments with disks at various elevations are of course of great interest.

From the account I have thus given of my experiments at Sodankylä, I think that all the subsidiary points which should be taken into account, as well as those questions which still await solution in connection with the aurora borealis, will be readily comprehended. It would, however, be of great advantage when making similar experiments to have two sets of apparatus; while thus measurements are being made with one, the variations in the current could be traced with the other, and thus the particulars requisite for a reduction to a fixed mean standard would be obtained.

$$
\text { SELIM LEMSTRÖM }
$$

Professor of the Helsingfors University

\section{HISTORICAL NOTES IN PHYSICS}

\section{I.-The Discovery of the Electric Light}

IN looking through an old volume of the Journal de Paris, I came across the following entry, for the date 22 Ventôse, An X. (March I2, 1802), which clearly relates to an exhibition of the electric arc light :-

"Le citoyen Robertson, auteur de la tantasmagorie, fait dans ce moment, des expériences intéressantes, et qui doivent sans doute avancer nos connoissances sur le galvanisme. Il vient de monter des piles métalliques, au nombre de 2500 plaques de zinc, et autant en cuivre rosette. Nous parlerons incessament de ses résultats, aussi que d'une expérience nouvelle qu'il a faite hier avec deux charbons ardens. Le premier étant placé à la base d'une colonne de 120 élémens de zinc et argent, et le second communiquant avec le sommet de la pile, ils ont donné, au moment de leur réunion, une étincelle brillante, d'une extrême blancheur, qui a été aperçue par toute la société. Le citoyen Robertson répétera cette expérience le $25 . "$

The individual who thus came before the public was named Etienne Gaspard Robertson, a name suggestive of Scotch descent. He was better known for his "Phantasmagoria," exhibited a few years later in London. Of this invention a notice appears earlier in the volume from which the above passage is taken; and in an earlier volume of the Fournal de Paris in the month "Fructidor, An viii.," there occurs a mention of some of his experiments on the couronne de tasses of Volta.

It is worthy of casual notice that in the number where Robertson's "Phantasmagoria" is advertised, the very next advertisement on the page is one of an exhibition to be given by Citoyen Martin at the Hôtel de Fermes, where- in as part of a "spectacle extraordinaire et amusant de physique," \&c., was to be shown "l'expérience du télégraphie plus rapide que la lumière, d'un effet extraordinaire et amusant."

The usual date given for the invention of the electric light by Sir Humphry Davy is 1809 ; but I was aware that earlier notices existed both in Cuthbertson's "Electricity" (1807) and other works. I was also under the impression that some earlier reference to the matter existed in Davy's own works. The finding of this notice in the Fournal de Paris induced me to consult the early volumes of the Philosophical Magazine and of Nicholson's Fournal.

In the Philosophical Magazine, vol. ix. p. 219, under the date February I, I80 I, the following passage occurs in a paper by $\mathrm{H}$. Moyes of Edinburgh, in which experiments with a voltaic pile or column are described :-

"When the above column was at the height of its strength its sparks were seen in the light of the day, even when taken with a piece of charcoal held in the hand."

In the fournal of the Royal Institution, vol. i. (1802), Davy describes (p. I06) some experiments on the spark yielded by the pile, and states: "When, instead of the metals, pieces of well-burned charcoal were employed, the spark was still larger and of a vivid whiteness." On p. 214 he describes and depicts an "apparatus for taking the galvano-electrical spark in fluids and aëriform substances." This apparatus consisted of a glass tube open at the top and having a tubulure at the side through which a wire tipped with charcoal was introduced, another wire, also tipped with charcoal, being cemented in a vertical position through the bottom.

But earlier than any of these is a letter printed at p. I 50 of Nicholson's Fournal for October, I80o. This letter is entitled "Additional Experiments in Galvanic Electricity, in a Letter to Mr. Nicholson." It is dated "Dowry Square, Hotwells, September 22, 1800," and is signed by Humphry Davy, who at that time was assistant to Dr. Beddoes at the old Philosophical Institution in Bristol. The letter begins thus :-

"SIR,-The earlier experimenters on animal electricity noticed the power of well-burned charcoal to conduct the common galvanic influence. I have found that this substance possesses the same properties as metallic bodies in producing the shock and spark,${ }^{1}$ when made a medium of communication between the ends of the galvanic pile of Signor Volta."

In none of these extracts, however, is anything said of the properties of the arc as a continuous luminous spark. These were made known in Davy's later researches. Yet the electric light attracted attention as we see before the special property of continuity was observed.

\section{II.-The Invention of the Telephone}

In the Journal of the Physical Society of Frankfort-onthe-Main for $1860-61$ (p. 57) may be found a memoir on telephony by the galvanic current, in which its writer says: "I have now succeeded in constructing an apparatus by means of which $I$ am in a position to reproduce the tones of divers instruments, and even to a certain degree the human voice." The inventor further says : "Since the length of the conducting wire may be extended for this purpose just as far as in direct telegraphy, I give to my instrument the name "telephone." "Towards the end of the memoir it is stated that until now it had not been possible to reproduce the tones of human speech with a distinctness sufficient to satisfy everybody: "The consonants are for the most part tolerably distinctly reproduced, but the vowels not yet to an equal degree." The author of the memoir in which these remarkable statements occur was Philipp Reis. The paper from which the preceding quotations have been taken contains many other points of interest, and in particular a com"Here Davy adds a footnote: "The spark is most vivid when the charcoal is hot." 
parison of the action of the transmitting part of the instrument with that of the human ear upon which it was founded. The author says: "How could a single instruinent reproduce at once the total action of all the organs operated in human speech? This was ever the cardinal question. At last I came by accident to put this question another way. How does our ear perceive the total (or

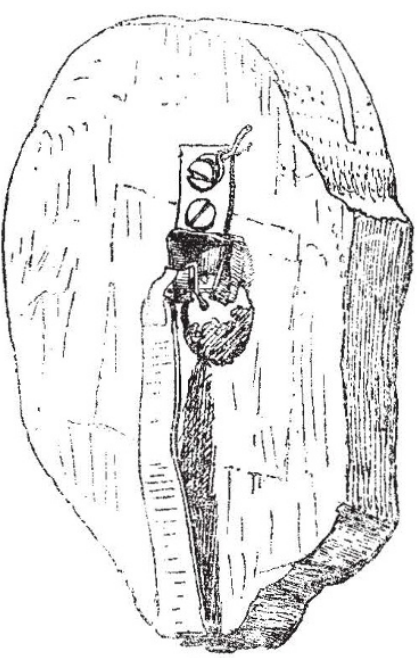

FIG. I.

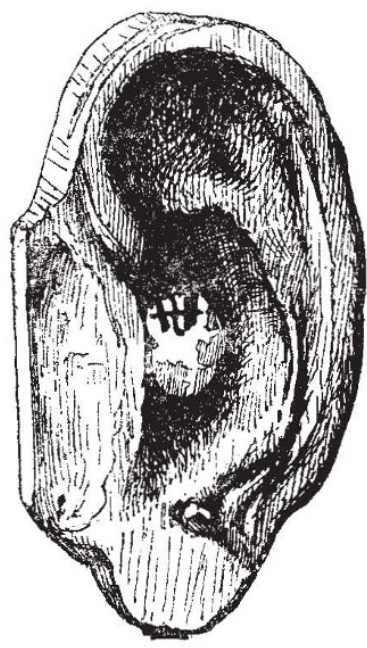

FIG. 2. resultant) vibrations of all the sinultaneously operant organs of speech?" He then goes on to describe the action of the auditory ossicles when made the recipients of sound-waves, and points out how they execute movements and exert forces upon one another in proportion to the condensations occurring in the sound-conducting medium and to the amplitudes of vibration of the tym-

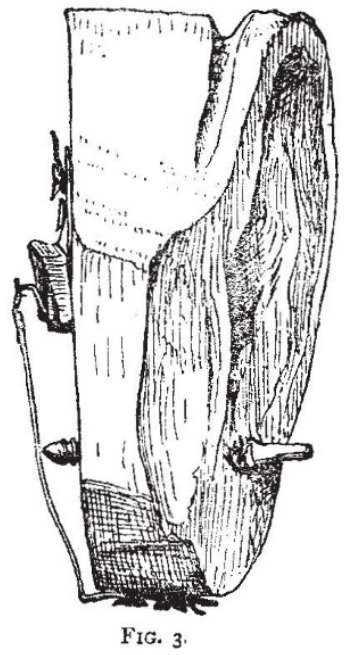

FIG. 3.

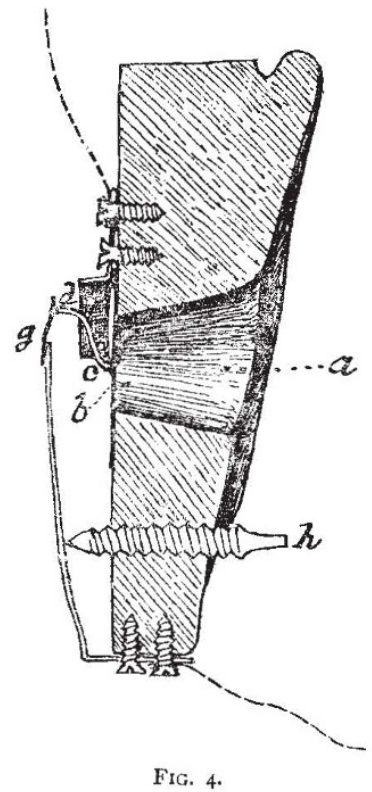

FIG. 4. panum. Having stated this law of proportion between the cause and its effect, he goes on to speak of the graphic method of representing varying forces, such as those of sound-waves, by curves; and emphatically lays down that the ear is absolutely incapable of perceiving anything more than can be expressed by such a curve. After giving samples of undulatory curves corresponding to musical tones and to discordant sounds he makes the following significant remark: "So soon therefore as it is possible, at any place and in any manner, to set up vibrations whose curves are like those of any given tone or combination of tones, we shall then receive the same impression which the tone or combination of tones would have produced upon us. Taking my stand upon the preceding principles, I have succeeded in constructing an apparatus," \&c. He concludes his paper by saying that the newly invented phonautograph of Duhamel may perhaps afford evidence as to the correctness of the views which he has asserted respecting the corresponfence between sounds and their curves.

The actual apparatus figured in this memoir and exhibited to the Frankfort society in October, $186 \mathrm{I}$, is now in my possession; and I have also temporarily intrusted to me a still earlier experimental telephone made by Philipp Reis in the form of a model of the human ear. ${ }^{1}$ This interesting instrument is depicted in its actual condition and size in Figs. I, 2, and 3, and in section in Fig. 4. It is carved in oak-wood. Of the tympanic membrane only small fragments now exist. Against the centre of the tympanum rested the lower end of a little curved lever of platinum wire, which represented the "hammer"-bone of the human ear. This curved lever was attached to the membrane by a minute drop of sealing-wax, so that it moved in correspondence with

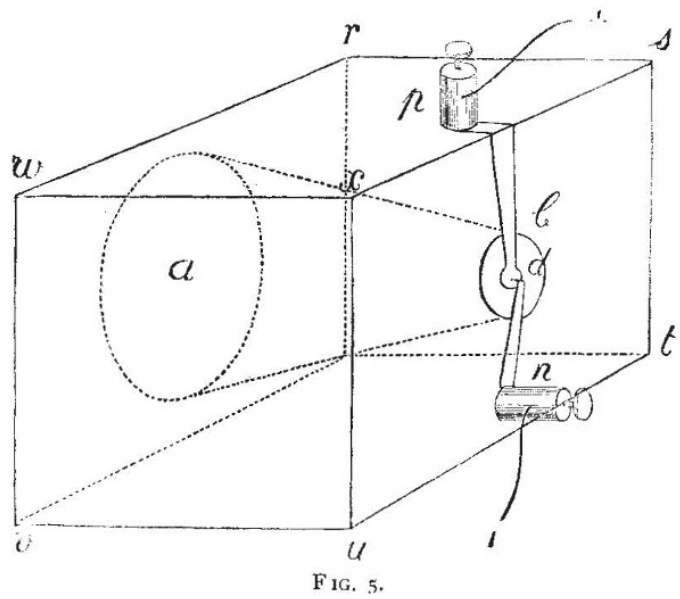

every movement of the tympanum. It was pivoted near its centre by being soldered to a sbort cross-wire serving as an axis. The upper end of the curved lever rested in loose contact against the upper end of a vertical spring, about $\mathrm{I}$ inch long, bearing at its summit a slender and resilient strip of platinum foil. An adjusting screw served to regulate the degree of contact between the vertical spring and the curved lever. Conducting wires, by means of which the current of electricity entered and left the apparatus were affixed to screws in connection respectively with the support of the pivoted lever and with the vertical spring.

If now any words or sounds of any kind were uttered in front of the ear, the membrane was thereby set into vibrations, as in the human ear. The little curved lever took up these motions precisely as the "hammer"-bone of the human ear does; and, like the "hammer"-bone, transferred them to that with which it was in contact. The result was that the contact between the upper end of the lever and the spring was caused to vary. With every rarefaction of the air the membrane moved forward, and the upper end of the little lever moved backward and pressed more firmly than before against the spring,

${ }^{x}$ The property of M. Léon Garnier. Director of Garnier's Institute at Fredrichsd urf, near Homburg, where Philipp Reiss was formerly Teacher of Natural Sciences. 
making better contact, and allowing a stronger current to flow. At every condensation of the air the membrane moved backward, and the upper end of the lever moved forward, so as to press less strongly than before against the spring, thereby making a less complete contact than before, and by thus partially interrupting the passage of the current, caused the current to flow less freely. The sound-waves which entered the air would in this fashion throw the electric current, which flowed through the point of variable contact, into undulations in strength. Reis himself termed the contact-part of his telephone an interruptor. That it was not intended to operate as an abrupt make-and-break arrangement, as some persons have erroneously fancied, is evident ; firstly, because the inventor introduced delicate springs to give a followingcontact, and so prevent abrupt breaks from occurring; secondly, because abrupt breaks would have violated the fundamental principle to which he refers in the sentence immediately preceding his description of the instrument shown to the Frankfort Society, namely that of creating tones whose curves were like the undulatory curves imparted at the transmitting end of the instrument; thirdly, because (in another article) he described his instrument as opening and closing the circuit in proportion to the sound-wave, which obviously an abrupt "break-andma'se" apparatus without a spring-contact could not possibly do. The mechanism which Reis thus invented -and which is substantially alike in all his instruments - might be appropriately described as the combination of a tympanum with an electric current-regulator, the essential principle of the electric current-regulator being the employment of a loose or imperfect contact between the two parts of the conducting system, those parts being so arranged that the vibrations of the tympanum would alter the degree of contact, and thereby vary the resistance offered at the point of contact to the passage of the current, and so regulate the strength of the current that it should magnetise and demagnetise the core of a distant electromagnet in a manner corresponding to the undulations of the tympanum of the transmitter.

The particular form of the instrument shown at Frankfort in I861, and described in the Fournal, is somewhat different from the "ear." The figure (5) and description are taken from the fournal.

"In a cube of wood, rstuvwx, there is a conical hole, $a$, closed at one side by the membrane, $b$ (made of the lesser intestine of the pig), upon the middle of which a little strip of platinum is cemented as a conductor of the current. This is united with the binding-screw, $p$. From the binding-screw, $n$, there passes likewise a thin strip of metal over the middle of the membrane, and terminates here in a little platinum wire, which stands at right angles to the length and breadth of the strip. From the binding-screw, $p$, a conducting-wire leads through the battery to a distant station."

In the original instrument there is also an adjusting. screw to regulate the contact, though this is not shown in the drawing.

The receiver used to reproduce the sounds transmitted by these telephones is also described in the memoir of Reis. It consisted of a steel needle surrounded by a coil of wire. This was at first set up for the purpose of increasing the sounds by resonance, upon the top of a violin; later it was mounted upon a pinewood box, to which still later a lid of thin pine was added against which th ? listener could press his ear. The sounds emitted by such a wire during magnetisation and demagnetisation were well known before, but to Reis is due the discovery thit other tones than the natural vibration-tone of the wire could be electrically imposed upon it by the varying magnetising force of the current in the surrounding coil. Reis explained the reproduction of the transmitted sounds by supposing a magnetic attraction between the atoms of the steel wire to work synchronously with the fluctuations of the current. He later devised a different receiver in which an electromagnet was provided with an elastically mounted armature of iron which it threw into vibrations corresponding to those of the original sound waves. With this apparatus and a transmitter with a small curved lever like that in the "ear," he was able (sec Kuhn's "Handbuch der Angewandten Elektricitätslebre," I866, p. IO2I) not only to reproduce melodies with astonishing exactness, and single words as in speaking and reading (less distinctly), but even to transmit the inflexions of the voice expressive of surprise, command, interrogation, \&c.

Considering how far these early researches were carried, it is remarkable that their historic value has been so greatly overlooked. Silvanus P. ThOMPSON

\section{SQUALLS}

I $\mathrm{N}$ a short calendar for the present year, issued by $\mathrm{Dr}$. Gustavus Hinrichs, ${ }^{1}$ are two interesting charts of the fronts of squalls passing over Iowa from north-west to south-east. He remarks that the lines between which 5 inch and I. inch of rain fell in one of these squallis on July 3I, I877, gradually diverge as the storm-front rolls down to the south-east, while bending more and more, so as strangely to recall the lines of equal timber in Eas:ern and Southern Iowa.

The lines showing the configuration of these squalls are very similar to those showing the shapes of the most extensive European squall, and the almost complete parallelism between the chart of the squall above alluded to, and those ${ }^{2}$ of the Eurydice squall, which traversed England on March 24, 1878, is worthy of the attention of meteorologists. Squalls of this description strictly deserve the name of "arched squalls" (apparently bestowed by English seamen on all squalls which are seen in perspective to rise as arches of cloud above the horizon), for when plotted out upon a chart they are found to be, at the period of their greatest development, scimitar or crescent-shaped, the central portion of the area of squall being in front of the right and left wings, and $\mathbf{a}$ chord of the arc so formed being commonly normal, or nearly so, to the isobars existing at the time. It seems probable thit the most projecting portion of the line of clouds forming the front of the squall traverses the line of steepest atmospheric gradients, but of this no proof has yet been furnished. The strongest wind is, in any case, commonly experienced in the immediate front of the squall along the line traversed by the focus of the squall, and the greatest precipitation in the rear is also usually experienced along this line. There is one characteristic which the crescent-shaped squall shares with the very local squalls common in the temperate latitudes in the rear of a depression, viz. the violent down-rush of cold air experienced under the front of the squall-cloud, followed by a comparative calm in its wake. In the crescent-shaped squall there is a veering of the lower wind and a backing of the upper wind, sometimes to the extent of about eight points, which is not traceable in the more local squall. In the crescent-shaped squall a sudden increase of atmospheric pressure is experienced at the earth's surface at the time of the strongest rush of wind. This characteristic seems to be shared by the majority of squalls which occur in the Persian Gulf and in Northern India from the north.west, and also by many squalls in the Indian and China seas (which may possibly prove to be of the crescent-shaped type); and it is precisely analogous to the rise of barometer frequently noticed at inland localities in the temperate zones during a summer thunderstorm. It is, however, stated that in

1 "Notes on the Cloud Forms and Climate of Iowa." Dr. G. Hinrichs, Director Iowa Weather Service.

${ }^{2}$ Meteorological Magazine, vol. xiii. p. 33; Nautical Magazine, vol. xlvii. 5 . 